\title{
IMPLEMENTATION OF SHORT-TERM FORECASTING MODELS IN THE NATURAL GAS INDUSTRY FINANCIAL DATA
}

\author{
Rialdi Azhar ${ }^{1}$, Sari Indah Oktanti Sembiring ${ }^{2}$, Muslimin Muslimin ${ }^{3}$, Fajrin Satria Dwi Kesumah ${ }^{4}$ \\ \{ rialdi.azhar@feb.unila.ac.id $^{1}$, sariindahoktanti@yahoo.co.id ${ }^{2}$, $\underline{\text { muslimin @yahoo.com }}^{3}$, and fajrinsatriagepare@gmail.com ${ }^{4}$ \}
}

Faculty of Economic and Bisnis, Universitas Lampung, Indonesia ${ }^{1}$, Faculty of Economic and Bisnis, Universitas Lampung, Indonesia ${ }^{2}$, Faculty of Economic and Bisnis, Universitas Lampung, Indonesia ${ }^{3}$, Faculty of Economic and Bisnis, Universitas Lampung, Indonesia ${ }^{4}$,

\begin{abstract}
Financial data especially the natural gas industry that will be projected must have high accuracy. Problems: These data are time-series data and contain heteroscedasticity so that they require forecasting models with low error rates. The data used in the study are daily financial data from natural gas from 2014 to 2019. Short-term forecasting model $(\mathrm{GARCH})$ which has the advantage of modeling data with heteroscedasticity. AR1, GARCH 1.1 short-term forecasting model is stated as a model that has the advantage of modeling data with a high degree of accuracy. The forecasting model can be used by various parties in finding the accuracy of information to come so that planning decisions have been prepared and prepared.
\end{abstract}

Keywords: Forecasting, GARCH, Natural Gas.

\section{Introduction}

Financial data are related to the interests of investment decision making, so projections are needed to identify earlier than signs. Early identification is very important because it can minimize the risk of decision making. Financial data forecasts in the form of daily prices, earnings, and shares are carried out to check information[1], [2].This study will focus on the daily price of natural gas. Daily prices play an important role as an indicator of the financial performance of a commodity. Daily prices provide a sign of the company's financial achievements, furthermore, it also provides an overview of external and internal conditions. Daily price forecasting can help investors and companies to evaluate and improve the quality of financial reporting as an estimated link to expected income and the amount of income that arises in the current year[3]. Forecasting related to daily prices has a high level of data volatility. Daily price volatility indirectly inhibits the level of risk that occurs in the market. Low daily price volatility will cause low movements in the market, which signals a low level of capital gains. Currently, statistical mathematical models are used in many economic practices to predict market conditions. One of the best models that will be used in this research is short-term forecasting using the GARCH Model. Forecasting will produce projections for the next 90 days based on data that has been collected previously. This study will use daily time-series data before the best GARCH model is selected, the data will be tested based on tests and assumptions. After the assumptions are tested and check the best GARCH model that is suitable based on the criteria will be selected for use in forecasting. This research focuses on forecasting financial data, especially in the natural gas industry. In the field of economics and business, forecasting is used to produce economic decisions that are more profitable, further, the purpose of this study is to design the best forecasting model for financial data of the natural gas industry, then the model is used to find out indications of rising and falling natural gas prices in the future. A statistical model with a high degree of accuracy is needed to get the right forecasting formula.

\section{Literature Review}

\subsection{Data Stationarity}

To check stationary data, besides looking at the time series data plot, statistical tests also use the Augmented Dicky Fuller Test (ADF Test). Time series data tend to be non-stationary, for example, price series data, non-stationary 
because there is no fixed level for prices. A series of non-stationary like this is called a unit-root nonstationary time series[4]. The root unit is a feature of several stochastic processes that can cause problems in time series modeling. The ADF test process is as follows: Significance level $(\alpha=0.05)$, Reject Ho if $\tau<-2.57$ or if p-value $<0.05$ [5].

\subsection{White Noise}

If a time series consists of observations that are not correlated (data) and have a constant variant, then we say that it is white noise[6]. If the time series is white noise, then the autocorrelation coefficient distribution of samples on lag $\mathrm{k}$ in large samples is a normal distribution with an average of 0 and variance $1 / \mathrm{T}$, where $\mathrm{T}$ is the number of observations.

\subsection{Testing for the ARCH / GARCH effect}

Estimating and testing parameters, to diagnose and test residues, and to choose the best model based on the least value criteria of AIC or SC. Residues obtained from the best ARMA models are examined using the Lagrange Multiplier (LM) test to find out whether they have an ARCH effect. If there is an ARCH effect, the data is modeled using the ARCH or GARCH models. The order of the ARCH or GARCH model is found through the squared residual plot of PACF.

\section{Methodology and data analysis}

Financial data in the form of the daily price of natural gas futures analyzed is the daily closing price. Data is taken from 1 January 2014 to 31 December 2019. The instrument for collecting data on the daily price of natural gas futures is done through the collection of available data available at www.investee.com. Research using SAS analysis tools with stationary orders, dereferencing, white noise, ARMA, ARCH, and then GARCH output.

\section{Research Result and Discussion}

\subsection{Check Stationarity of Data}

The first step that needs to be taken in the time series data is to conduct stationarity tests to ensure the data does not contain time on variants, covariants, and other variables [5]. The plot that can display the data is the most common way to see the stationarity of the data. See Figure 1. Crude Oil Data from 2015 to 2020 (accessed 2020) to see the data in the display line (line graph)with daily data natural gas industry:

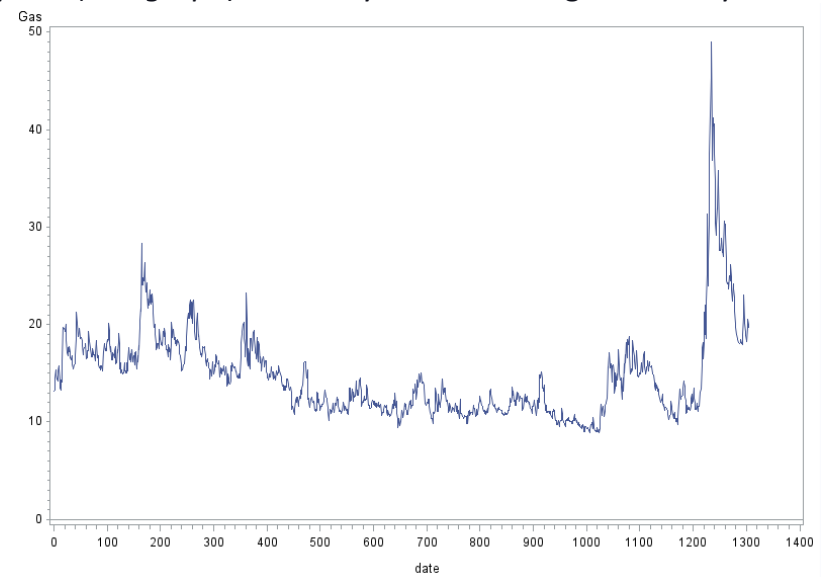

Figure 1. Crude Oil Data from 2015 to 2020 (accessed 2020)

Looking at data from the plot chart is a method with a high degree of subjectivity of the researcher. Deeper, suggested statistical tests to carry out stationary data checks can also be used. Augmented Dicky Fuller (ADF) -test can show statistical analysis of data by considering stationarity. In the following table 4.1 we can see the results of data processing using SAS. 
Table 4.1. Augmented Dickey-Fuller UnitTest Roots

\begin{tabular}{cccccccc}
\hline Type & Lags & Rho & Pr $<$ Rho & Tau & Pr $<$ Tau & F & Pr $>$ F \\
\hline Zero Mean & $\mathbf{3}$ & -17.286 & 0.3643 & -0.8723 & 0.3389 & & \\
Single Mean & $\mathbf{3}$ & -220.977 & 0.0071 & -32.536 & 0.0178 & 52.978 & 0.0276 \\
Trend & $\mathbf{3}$ & -220.972 & 0.0448 & -32.316 & 0.079 & 52.889 & 0.1103 \\
\hline
\end{tabular}

Results from the Augmented Dickey-Fuller (ADF) unit-root test statistic in table 4.1 show the p-value above 0.05 $(0.3389>0.05 ; 0.0178 ; 0.079>0.05)$. These results signal that the crude oil price data used is indicated to be nonstationary. The next test is to see the value of ACF. Table 4.2 shows the value for intercept $($ Ho: Intercept $=0)$ is very significant with $\mathrm{p}$-value $<0.0001$.

Table 4.2. Estimated Parameters for Intercepts

\begin{tabular}{lccccc}
\hline \multicolumn{5}{c}{ Parameter Estimates } \\
\hline Variable & DF & Estimate & Standard & t Value & Approx \\
\cline { 4 - 4 } \cline { 5 - 6 } & & & Error & & Pr> | t | \\
\hline Intercept & 1 & 147,357 & 0.129 & 114.26 & $<.0001$ \\
\hline
\end{tabular}

Table 4.2 Shows that the test statistics for intercept (Ho: intersept $=0$ ) are all very significant with all p-values $<0,0001$. This means that all intercepts are different from zero.
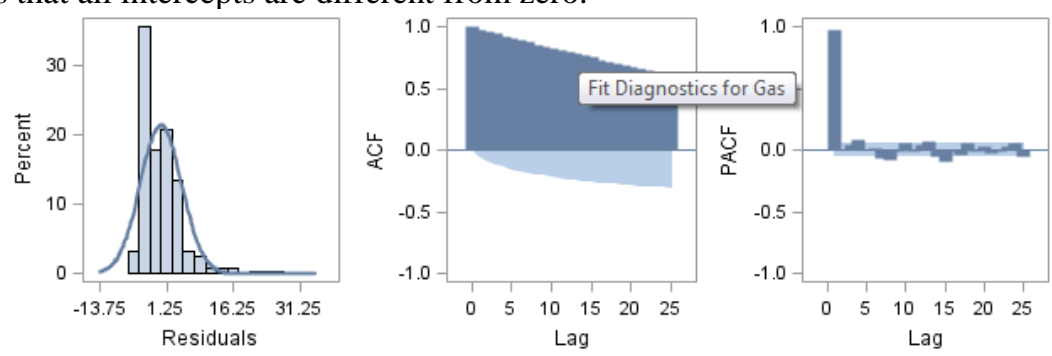

Figure 2 Correlation Analysis for Gas Industry Data

Figure 2. Correlation Analysis for Gas Industry Data attempts to show the certainty of the level of stationarity from the daily data of the natural gas industry. Seeing from the plot plots we can judge whether the data is stationary or non-stationary. Figure 4 for daily data on the natural gas industry with the Autocorrelation Function (ACF) shows that this series is non-stationary because ACF decays very slowly. Virginia, et al.,and Azhar, et al., on research show that ACF can be used as an indicator that marks data to identify stationarity[7], [8].

In-depth research on models with a high degree of accuracy requires a test white noise convincing. This is because research on a special level requires an error rate in the range of 0 (zero). By ignoring the white noise the researcher decides to difference the data to get confidence in the stationary data. the next step is to convert it into a stationary series by differentiating. By using differencing with lag $=2(\mathrm{~d}=2)$.

Table 4.3 White Noise Data

\begin{tabular}{ccccccccccc}
\hline \multicolumn{1}{c}{ Autocorrelation Check for White Noise } \\
\hline To Lag & Chi-Square & DF & Pr > ChiSq & \multicolumn{7}{c}{ Autocorrelations } \\
\hline $\mathbf{6}$ & 6796.29 & 6 & $<.0001$ & 0.978 & 0.957 & 0.938 & 0.923 & 0.907 & 0.893 \\
\hline $\mathbf{1 2}$ & 9999.99 & 12 & $<.0001$ & 0.876 & 0.856 & 0.836 & 0.82 & 0.804 & 0.79 \\
\hline $\mathbf{1 8}$ & 9999.99 & 18 & $<.0001$ & 0.779 & 0.765 & 0.747 & 0.73 & 0.712 & 0.697 \\
\hline $\mathbf{2 4}$ & 9999.99 & 24 & $<.0001$ & 0.683 & 0.67 & 0.654 & 0.638 & 0.623 & 0.612 \\
\hline
\end{tabular}

Table 4.3 which shows the hypothesis of white noise can be rejected with the condition that $\mathrm{P}<0,0001$. This indicates that the crude oil price data is included in the non-stationary data group. Table 4.4 shows stationary data after dereferencing. 


\subsection{Data Defferensing Process}

Stationarity can be seen from the behavior of residual data after the difference is distributed around 0 (zero). Figure 3 shows that the graph shows the average movement of data around 0 . This shows that the data has been deposited with the treatment of differentiation. Figure 3. Residual plots, ACF, PACF, and IACF after differentiation with $\mathbf{d}=\mathbf{2}($ differencing with lag $=2)$ shows it clearer:
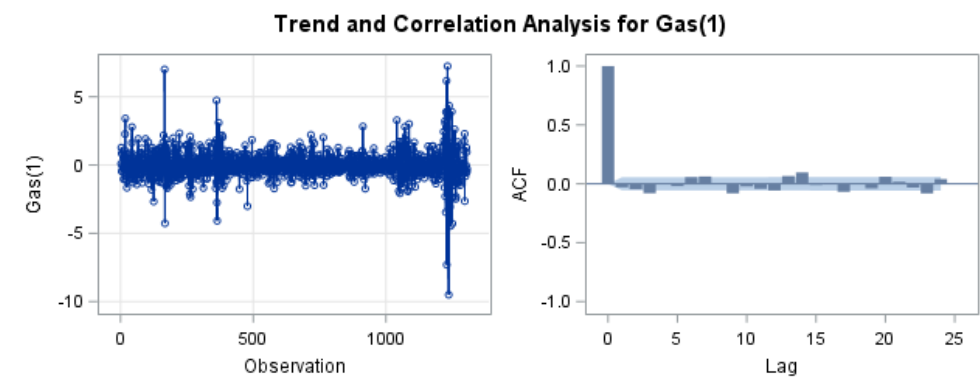

Figure 3. Residual plots, ACF, PACF, and IACF after differentiation with $\mathrm{d}=2($ differencing with lag $=2)$

Can be seen from the behavior of ACF decrease in fast plots, if yes then the data shows that changes in the industry daily price data natural gas, assuming $\mathrm{d}=2$ each, the change data shows stationary series data.

\subsection{Testing ARCH Effects ARCH}

Lagrange multiplier tests can be used to check for the presence of heteroscedasticity or the effects of ARCH. The following table is the result of the ARCH effect.

Table 5. ARCH Lagrange Multiplier Test Gas Industry Financial Data

Tests for ARCH disturbances Based on OLS Residuals

\begin{tabular}{ccccc}
\hline Order & $\mathbf{Q}$ & Pr>Q & LM> & Pr LM \\
\hline 1 & 2113327 & $<.0001$ & $2,096,258$ & $<.0001$ \\
\hline 2 & 2845038 & $<.0001$ & 2.217 .306 & $<.0001$ \\
\hline 3 & $4,411,783$ & $<.0001$ & $3,015,969$ & $<.0001$ \\
\hline 4 & $5,093,654$ & $<.0001$ & $3,023,049$ & $<.0001$ \\
\hline 5 & $5,293,565$ & $<.0001$ & $3,026,705$ & $<.0001$ \\
\hline 6 & $5,479,775$ & $<.0001$ & $3,026,909$ & $<.0001$ \\
\hline 7 & $6,067,586$ & $<.0001$ & $3,238,155$ & $<.0001$ \\
\hline 8 & $6,181,551$ & $<.0001$ & $3,260,535$ & $<.0001$ \\
\hline 9 & $6,511,479$ & $<.0001$ & $3,417,966$ & $<.0001$ \\
\hline 10 & $7,212,268$ & $<.0001$ & $3,504,276$ & $<.0001$ \\
\hline 11 & $7,528,215$ & $<.0001$ & $3,508,581$ & $<.0001$ \\
\hline 12 & $7,588,522$ & $<.0001$ & $3,567,597$ & $<.0001$
\end{tabular}

Table 5 presents the Portmanteau Q and Lagrange Multiplier Test for the ARCH effect. Q statistics have been calculated from squared residuals and are used to test the non-linear effects (for example, the GARCH effect) present in residuals. From the test statistics, Portmanteau Q and Lagrange Multiplier Tests researchers can reject Ho with the conditions shown in table 5 with a $p$-value of less than 0,0001 . Therefore, it can be concluded that the gas industry financial data is identified as having an ARCH effect. This conclusion is also supported by the behavior of conditional variants for financial data on the gas industry in Figure 4. Conditional Variance (Volatility) and Forecast from the Natural Gas Industry Daily Data. Further studies require a model that can overcome the problem of heteroscedastic variance. In this case we will use the ARCH / GARCH model to explain data behavior. 


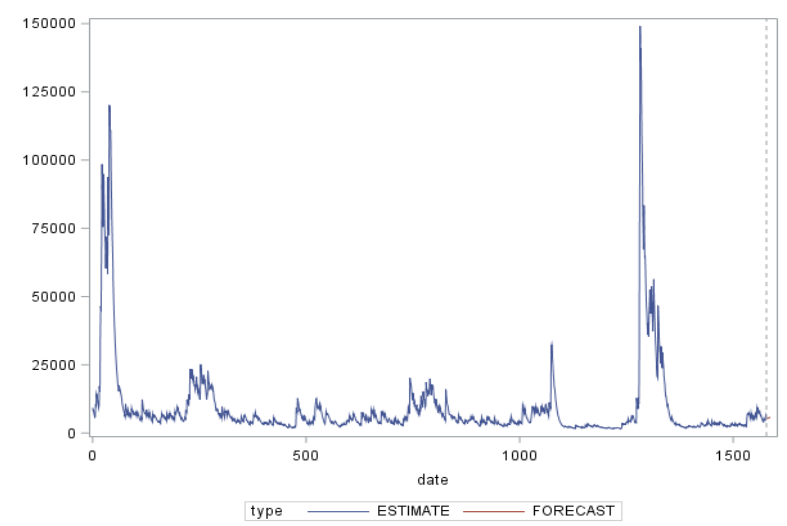

Figure 4. Conditional Variance (Volatility) and Forecast from the Natural Gas Industry Daily Data.

\subsection{Autoregressive Modeling - GARCH (AR-GARCH) The}

ARCH's effect on the gas industry's financial data gives a signal to apply the GARCH model. With this model, it is assumed that the nature of heteroskedasticity can be generalized. The following detailed statistics forecasting the gas industry financial data with the GARCH model:

Table 6. Estimated Statistics GARCH data daily data of the natural gas industry.

\begin{tabular}{ccccccccc}
\hline SSE & MSE & Obs. & Log Likelihood & SBC & MAE & MAPE & Total R-Square & Pr>ChiSq \\
\hline 14285454 & 9053 & 1578 & $-90,714,511$ & $181,797,219$ & $629,504,541$ & $204,506,841$ & 0.9825 & $<.0001$ \\
\hline
\end{tabular}

Based on table 6. above shows the error rate of the model, and table 7. below can be summarized the main models from the results of processing the financial industry gas data are as follows:

$$
G A S_{t}=4222-09992 G A S_{t-1}+\mathrm{E}_{t}
$$

And the model of variance is as follows:

$$
\sigma_{\mathrm{t}}^{2}=1,145,838+0.1197 \varepsilon_{\mathrm{t}-1}^{2}+0.8709 \sigma_{\mathrm{t}-1}^{2}
$$

\begin{tabular}{|c|c|c|c|c|c|}
\hline \multirow[t]{2}{*}{ Variable } & \multirow[t]{2}{*}{ DF } & \multirow[t]{2}{*}{ Estimate } & Standard & \multirow[t]{2}{*}{ t Value } & Approx \\
\hline & & & Error & & $\operatorname{Pr}>|t|$ \\
\hline Intercept & 1 & 4222 & $7,630,730$ & 5.53 & $<.0001$ \\
\hline AR1 & 1 & -0.9992 & 0.001146 & -871.72 & $<.0001$ \\
\hline ARCH0 & 1 & 1.145 .838 & 316.350 & 3.62 & 0.0003 \\
\hline ARCH1 & 1 & 0.1197 & 0.009268 & 12.92 & $<.0001$ \\
\hline GARCH1 & 1 & 0.8709 & 0.009665 & 90.11 & $<.0001$ \\
\hline
\end{tabular}

Table 7. Estimated Parameters of AR Model (1) -GARCH (1,1)

Financial data for the gas industry is a reference. basis in determining the selling price. With the right prediction model, it is expected that the preparation of decision making especially related to data can produce decisions with low errors. Table 8 shows the results of forecasting the financial data of the gas industry, the trend tends to rise.

\begin{tabular}{|c|c|c|c|c|c|c|c|}
\hline Date & u1 & u_garch & p_garch1 & PriceGAS & l_garch & 11 & r_garch1 \\
\hline 1579 & 1578 & 2332.33 & . & 2190.71 & . & . & 2049.09 \\
\hline 1580 & 1579 & 2393.31 & . & 2192.41 & . & . & 1991.52 \\
\hline 1581 & 1580 & 2440.90 & . & 2194.12 & . & . & 1947.33 \\
\hline 1582 & 1581 & 2481.63 & . & 2195.82 & . & · & 1910.01 \\
\hline 1583 & 1582 & 2518.01 & . & 2197.52 & . & . & 1877.04 \\
\hline 1584 & 1583 & 2551.31 & . & 2199.22 & . & . & 1847.13 \\
\hline 1585 & 1584 & 2582.31 & . & 2200.92 & . & . & 1819.54 \\
\hline 1586 & 1585 & 2611.49 & . & 2202.62 & . & . & 1793.75 \\
\hline
\end{tabular}

Table 8. Forecasting Data 


\begin{tabular}{llllllll}
\hline 1587 & 1586 & 2639.19 &. & 2204.32 &. &. & 1769.44 \\
\hline 1588 & 1587 & 2665.67 &. & 2206.01 &. & & .
\end{tabular}

\section{Summary}

Based on an analysis of data on the daily price of the natural gas industry futures from 1 January 2014 to 31 December 2019 shows that the AR1 model, GACRH 1.1 can be classified as the chosen model. Model AR1, GARCH 1.1 processes the modeling quite well. The model has a confidence level of more than Ninety percent $(98 \%)$. With a forecast period of 30 days the price of natural gas futures shows an increasing trend.

\section{Implications / Limitations and Suggestions for Further Research}

High-level forecasting can be used as an aid in the economic field in making appropriate decisions.

\section{REFERENCES}

[1] M. B. Ali and T. A. Chowdhury, "Effect of Dividend on Stock Price in Emerging Stock Market: A Study on the Listed Private Commercial Banks in DSE,” Int. J. Econ. Financ., vol. 2, no. 4, pp. 52-64, 2010.

[2] Y. Hao, L. O. Wang, and C. C. Lee, "Financial development, energy consumption and China's economic growth: New evidence from provincial panel data," Int. Rev. Econ. Financ., 2020.

[3] W. Beaver, R. Lambert, and D. Morse, “The information content of security prices,” J. Account. Econ., 1980.

[4] R. S. Tsay, Analysis of Financial Time Series: Third Edition. 2010.

[5] L. Seymour, P. J. Brockwell, and R. A. Davis, "Introduction to Time Series and Forecasting.," J. Am. Stat. Assoc., 1997.

[6] M. Geurts, G. E. P. Box, and G. M. Jenkins, “Time Series Analysis: Forecasting and Control,” J. Mark. Res., 1977.

[7] E. Virginia, J. Ginting, and F. A. M. Elfaki, "Application of garch model to forecast data and volatility of share price of energy (Study on adaro energy Tbk, LQ45),” Int. J. Energy Econ. Policy, 2018.

[8] R. Azhar, F. S. D. Kesumah, Ambya, F. K. Wisnu, and E. Russel, "Application of short-term forecasting models for energy entity stock price: evidence from Indika Energi Tbk, Jakarta islamic index,” Int. J. Energy Econ. Policy, 2020. 